\title{
Aquaporin 4 Suppresses Neural Hyperactivity and Synaptic Fatigue and Fine-Tunes Neurotransmission to Regulate Visual Function in the Mouse Retina
}

\author{
Yoko Ozawa ${ }^{1,2}$ (D) Eriko Toda $^{1} \cdot$ Hirohiko Kawashima ${ }^{1,2} \cdot$ Kohei Homma $^{1} \cdot$ Hideto Osada $^{1} \cdot$ Norihiro Nagai $^{1,2}$. \\ Yoichiro Abe $^{3}$ - Masato Yasui ${ }^{3} \cdot$ Kazuo Tsubota $^{2}$
}

Received: 29 March 2019 / Accepted: 22 May 2019/Published online: 12 June 2019

(C) The Author(s) 2019

\begin{abstract}
The bidirectional water channel aquaporin 4 (AQP4) is abundantly expressed in the neural tissue. The advantages and disadvantages of AQP4 neural tissue deficiency under pathological conditions, such as inflammation, and relationship with neural diseases, such as Alzheimer's disease, have been previously reported. However, the physiological functions of AQP4 are not fully understood. Here, we evaluated the role of AQP4 in the mouse retina using Aqp4 knockout (KO) mice. Aqp4 was expressed in Müller glial cells surrounding the synaptic area between photoreceptors and bipolar cells. Both scotopic and photopic electroretinograms showed hyperactive visual responses in $\mathrm{KO}$ mice, gradually progressing with age. Moreover, the amplitude reduction after frequent stimuli and synaptic fatigue was more severe in KO mice. Glutamine synthetase, glutamate aspartate transporter, synaptophysin, and the inward potassium channel Kir2.1, but not Kir4.1, were downregulated in KO retinas. KIR2.1 colocalized with AQP4 in Müller glial cells at the synaptic area, and its expression was affected by Aqp4 levels in primary Müller glial cell cultures. Intraocular injection of potassium in wild-type mice led to visual function hyperactivity, as observed in Aqp4 KO mice. Mitochondria molecules, such as Pgcl $\alpha$ and CoxIV, were downregulated, while apoptotic markers were upregulated in KO retinas. AQP4 may fine-tune synaptic activity, most likely by regulating potassium metabolism, at least in part, via collaborating with KIR2.1, and possibly indirectly regulating glutamate kinetics, to inhibit neural hyperactivity and synaptic fatigue which finally affect mitochondria and cause neurodegeneration.
\end{abstract}

Keywords Aquaporin $4 \cdot$ Neural hyperactivity $\cdot$ Synaptic fatigue $\cdot$ Retina $\cdot$ Potassium $\cdot$ Glutamate

\section{Introduction}

The bidirectional water channel aquaporin 4 (AQP4) is widely distributed in the plasma membrane and maintains the tissue

Yoko Ozawa and Eriko Toda contributed equally to this work.

Electronic supplementary material The online version of this article (https://doi.org/10.1007/s12035-019-01661-2) contains supplementary material, which is available to authorized users.

Yoko Ozawa

ozawa@a5.keio.jp

1 Laboratory of Retinal Cell Biology, Department of Ophthalmology, Keio University School of Medicine, 35 Shinanomachi, Shinjukuku, Tokyo 160-8582, Japan

2 Department of Ophthalmology, Keio University School of Medicine, 35 Shinanomachi, Shinjukuku, Tokyo 160-8582, Japan

3 Department of Pharmacology, Keio University School of Medicine, 35 Shinanomachi, Shinjukuku, Tokyo 160-8582, Japan microenvironment by supporting molecular transfer between extracellular and intracellular spaces [1-3]. Although the vulnerability or advantages of its deficiency in neural tissue have been reported under pathological conditions [4-8], its physiological function is not fully understood [9].

The aquaporin family (AQP0-12) has been well investigated in the kidney $[1,2,10,11]$, where water permeability is well controlled in each part of the nephron; each AQP is localized in a specific part of the nephron to regulate water kinetics. Among AQPs, AQP4 is a polypeptide encoded by a brainderived cDNA and constitutes the predominant water channel protein in neural tissue [10]. AQP4 regulates extracellular space volume, waste clearance, and calcium ion signaling, as well as potassium buffering [12]. Its expression is reportedly downregulated in pathological lesions in neuromyelitis optica, an inflammatory and necrotizing neural disease clinically characterized by selective involvement of the optic nerves and spinal cord [13]. Serum anti-AQP4 autoantibodies are frequently found in severe, recurrent autoimmune optic neuritis, namely neuromyelitis optica spectrum disorder [14], and may determine the disease 
severity [15]. AQP4 protein is increased in the intraocular fluid of diabetic patients [16], and its relationship with diabetes is well reported in mice $[6,7,10,17]$. AQP4 is induced in the retina of diabetic mice [18] and suppresses inflammation [17]. Another report showed that, while AQP4 is increased in the retina of these mice, the potassium channel subunit KIR4.1 is downregulated, thus inducing disruption of the blood-retina barrier and resulting in edema and inflammation [19]. Colocalization of AQP4 and KIR4.1 in astrocyte end feet has been shown to regulate bloodbrain barrier function, and the relationship between AQP4 and blood vessels is well accepted [20, 21].

In contrast, while AQP4 is expressed in neural tissue, its impact on neural functions is still under debate. AQP4 may mediate the clearance of amyloid beta peptides related to Alzheimer's disease [22] and regulate extracellular space volume during synaptic activity [23]. In the retina, AQP4 is expressed in Müller glial cells [24] which not only provide structural support but also maintain homeostasis of the retinal microenvironment and regulate neuronal activity [25]. A retinal phenotype of Aqp4 deficiency in mice was reported using electroretinogram (ERG), which measures visual function; the function was comparable between wild-type (WT) and knockout $(\mathrm{KO})$ mice at early time point after birth, postnatal day 17 [8], but a clear impairment was observed in aged mice at 10 months [26]. However, the development of this neural dysfunction and the underlying mechanisms remain obscure.

In the current study, we explored the impact of AQP4 in keeping neuronal homeostasis and synaptic function in the mouse retina. For this purpose, we assessed AQP4 expression in the retina, performed ERG in relatively young adult Aqp4 $\mathrm{KO}$ mice to evaluate visual function, and examined the expression of synaptic markers, mitochondria molecules, and apoptotic markers.

\section{Materials and Methods}

\section{Animals}

Male Aqp4 KO mice generated as described previously [5, 27] (acc. no. CDB0758 K: http://www.cdb.riken.jp/arg/mutant\% 20mice\%20list.html), and back crossed to C57B6J background, were maintained in an air-conditioned room $\left(22^{\circ} \mathrm{C}\right)$ under a $12-\mathrm{h}$ light/dark cycle (lights on from 8 a.m. to 8 p.m.) with free access to food and water, at the animal facility of Keio University School of Medicine. All animal experiments were conducted in accordance with the ARVO Statement for the Use of Animals in Ophthalmic and Vision Research and the guidelines of the Animal Care Committee of Keio University. For each experiment, KO and WT mice were serially numbered, and the examiners were blind to genotype when recording the results at the time of experiments. Overall, no clear differences in body weight and size were observed in $\mathrm{KO}$ mice (data not shown).

\section{Immunohistochemistry}

Mouse eyes were enucleated and fixed in $4 \%$ paraformaldehyde overnight at $4{ }^{\circ} \mathrm{C}$. After fixation, the eyes were embedded in paraffin (Sakura Finetek Japan, Tokyo, Japan), and 6to 8 - $\mu \mathrm{m}$-thick sections including the optic nerve head to the most peripheral region of the retina were prepared and deparaffinized. The sections were blocked with TNB blocking buffer (0.1 M Tris- $\mathrm{HCl}$ [pH 7.5] and $0.15 \mathrm{M} \mathrm{NaCl})$ for $30 \mathrm{~min}$ at room temperature and then incubated overnight with antibodies for AQP4 (Sigma-Aldrich, St. Louis, MO; or the one generated by Ramadhanti et al.) [28], glutamine synthetase (GS; Millipore, Burlington, MA), synaptophysin (DAKO, Agilent Technologies, Santa Clara, CA), postsynaptic density protein 95 (PSD95; Thermo Fisher Scientific, Waltham, MA), bassoon (Enzo Biochem, Inc., Farmingdale, NY), and KIR 2.1 (Abcam, Cambridge, UK). Then, sections were incubated with Alexa 488-conjugated or Alexa 555-conjugated secondary antibodies (Invitrogen Japan, Tokyo, Japan) with subsequent counterstaining with DAPI solution $(2 \mu \mathrm{g} / \mathrm{mL})$ for $1 \mathrm{~h}$ at room temperature. Sections from eight animals were examined under a microscope equipped with a digital camera (Olympus Co., Tokyo, Japan), and fluorescent images were obtained using a confocal microscope (TCS-SP5; Leica, Tokyo, Japan).

\section{ERG Recordings}

Mice were dark-adapted for at least $12 \mathrm{~h}$ and then placed under dim-red illumination before conducting the ERGs. Mice were anesthetized with intraperitoneal combined anesthetics [midazolam $4 \mathrm{mg} / \mathrm{kg}$ of body weight (BW) (Sandoz Japan, Tokyo, Japan), medetomidine $0.75 \mathrm{mg} / \mathrm{kg}$ BW (Nippon Zenyaku Kogyo Co., Ltd., Fukushima, Japan), butorphanol tartrate 5 mg/kg BW (Meiji Seika Pharma Co., Ltd., Tokyo, Japan)] and kept on a heating pad throughout the experiment. Mouse pupils were dilated using a single drop of a mixture of tropicamide and phenylephrine $(0.5 \%$ each; Mydrin- $\mathrm{B}$; Santen, Osaka, Japan). The ground and reference electrodes were then placed on the tail and in the mouth, respectively, while the active gold wire electrodes were placed on the cornea.

Recordings were made using a PowerLab System 2/25 (AD Instruments, New South Wales, Australia). Full-field scotopic ERGs were measured in response to a flash stimulus at intensities ranging from -2.1 to $2.9 \log \mathrm{cd} \mathrm{s} / \mathrm{m}^{2}$. Photopic ERGs were measured after 10 min of light adaptation. Flash stimuli ranging from 0.4 to $1.4 \log \mathrm{cd} \mathrm{s} / \mathrm{m}^{2}$ were used for recordings with a background of $30 \mathrm{~cd} \mathrm{~s} / \mathrm{m}^{2}$ (PowerLab System 2/25, AD Instruments, New South Wales, Australia), and the results of 20 single-flash trace trials were averaged. Dark-adapted flicker ERGs [29] were recorded using repeated stimuli at $0.4 \log \mathrm{cd} \mathrm{s} / \mathrm{m}^{2}$ with a frequency ranging from 0.5 to 
$30 \mathrm{~Hz}$ for $600 \mathrm{~ms}$, and the first and 20th waves of continuous recordings were analyzed. The responses were differentially amplified and filtered through a digital bandpass filter ranging from 0.3 to $1000 \mathrm{~Hz}$. Each stimulus was delivered using a commercial stimulator (Ganzfeld System SG-2002; LKC Technologies, Inc., Gaithersburg, MD). The a-wave amplitude was measured from the baseline to the trough, while the bwave amplitude was measured from the trough of the a-wave to the peak of the b-wave. The implicit times of the a- and bwaves were measured from the onset of the stimulus to the peak of each wave. The peak points were automatically indicated by the system and confirmed by the examiner. In each recording, four to five $\mathrm{KO}$ and WT animals were used.

\section{Real-Time Reverse Transcription-Polymerase Chain Reaction}

Total RNA was isolated from mouse retinas at 16 weeks of age using TRIzol reagent (Life Technologies, Carlsbad, CA, USA). RNA concentration was measured using NanoDrop 1000 (Thermo Fisher Scientific), and $1 \mu \mathrm{g}$ RNA was reverse-transcribed using the SuperScript VILO master mix (Life Technologies, Carlsbad, CA, USA), according to the manufacturer's instructions. The following primer sequences were used: glyceraldehyde 3-phosphate dehydrogenase (Gapdh), forward 5'-AACTTCGGCCCCATCTTCA-3' and reverse 5'-GATGACCCTTTTGGCTCCAC-3'; GS, forward 5'-ACTGTGAGCCCAAGTGTGTG-3' and reverse 5'GGAGGTACATGTCGCTGTTG-3'; glutamate aspartate transporter (Glast), forward 5'-GAGCCTCACCAAGG AAGATG-3' and reverse 5'-CCTCCCGGTAGCTCATTTTA $-3^{\prime}$; synaptophysin, forward 5'-GCATTGCTGATGCTGCTG$3^{\prime}$ and reverse 5'-CACCTTCACGAAGCCAAGG-3'; peroxisome proliferator-activated receptor gamma coactivator 1alpha $(P g c l \alpha)$, forward 5'-GATGAATACCGCAA AGAGCA- $3^{\prime}$ and reverse 5'-AGATTTACGGTGCATTCCT3'; cytochrome c oxidase subunit 4 (CoxIV), forward 5'CGACTGGAGCAGCCTTTCC-3' and reverse 5'-CTGT TCATCTCGGCGAAGC-3'; cytochrome c $(C y t C)$, forward 5'-CCAGGCTGCTGGATTCTCTTACACA-3' and reverse 5'-TCCAAATACTCCATCAGGGTATCC-3'; heme oxygenase 1 (Ho-1), forward 5'-ACGCATATACCCGCTACCTG-3' and reverse 5'-CCAGAGTGTTCATTCGAGCA-3'; fission 1 (Fis 1), forward 5'-ATATGCCTGGTGCCTGGTTC-3' and reverse 5'-AGTCCCGCTGTTCCTCTTTG-3'; mitofusin 1 $(M f n 1)$ forward 5'-GATGTCACCACAGAGCTGGA-3' and reverse 5'-AGAGCCGCTCATTCACCTTA-3'; mitofusin 2 (Mfn2), forward 5'-CCCCTCTCAAGCACTTTGTC-3' and reverse 5'-ACCTGCTCTTCCGTGGTAAC-3'; sulfonylurea receptor 1 (Sur 1) forward 5'-ctgctctttgtcctggtgtg-3' and reverse 5'-cagctggcatgtacaaatgg; and potassium channel, subfamily K, member 3 (also known as Task-1), forward 5'gctccttctacttcgccatc- $3^{\prime}$ and reverse $5^{\prime}$-gaacatgcagaacacettgc.
Taqman probes (Applied Biosystems, Thermo Fisher Scientific) were used for Kir2.1 (also known as Kcnj2, potassium inwardly rectifying channel, subfamily $\mathrm{J}$, member 2 ; Mm00434616), Aqp4 (Mm00802131), Kir4.1 (also known as Kcnj10, potassium inwardly rectifying channel, subfamily $\mathrm{J}$, member 10; Mm00445028), potassium channel, subfamily V, member 2 (Kcnv2; Mm00807577), b cell lymphoma 2 (bcl2; Mm00477631), and BCL2-associated X protein (Bax; Mm00432050). Real-time PCR was performed using the StepOnePlus ${ }^{\mathrm{TM}}$ PCR system (Applied Biosystems, Thermo Fisher Scientific), and gene expression was quantified using the $\Delta \Delta \mathrm{CT}$ method. All mRNA levels were normalized to those of Gapdh. For expression analysis, five to ten $\mathrm{KO}$ and WT animals or four to five culture samples with or without knockdown (KD) of Aqp 4 (see below) were analyzed. All the real-time reverse transcription-polymerase chain reaction (RTPCR) reactions using the SYBR systems were performed after validating the primers by checking whether the melting curves show a single peak (data not shown), and those using Taqman probes were done following the manufacturer's protocol.

\section{Cell Culture}

Primary Müller glial cell culture was performed as previously reported [30] with some modifications. Briefly, Müller glial cells were isolated from the retinas of $\mathrm{C} 57 \mathrm{BL} / 6$ mice at postnatal days 7-12. After the eyes were enucleated, the retinas were isolated and incubated in $0.1 \%$ trypsin/EDTA (Gibco, Thermo Fisher Scientific) at $37{ }^{\circ} \mathrm{C}$ for $30 \mathrm{~min}$. Retinal cells were dissociated by pipetting and maintained for a few days in Dulbecco's modified Eagle's medium containing high glucose $(4500 \mathrm{mg} / \mathrm{L})$ and Ham's nutrient mixture F-12 medium (Gibco, Carlsbad, CA) supplemented with $10 \%$ fetal bovine serum, penicillin (100 units/mL), and streptomycin $(100 \mu \mathrm{g} /$ $\mathrm{mL}$ ), at $37{ }^{\circ} \mathrm{C}$, under a humidified atmosphere with $5 \% \mathrm{CO}_{2}$, to selectively purify Müller glial cells.

To knockdown Aqp4 in Müller glial cells, we introduced Aqp4 siRNA (MSS202139, Thermo Fisher Scientific), while control siRNA (Negative Control Lo GC, Thermo Fisher Scientific) was introduced as negative control, using Lipofectamine RNAiMAX Reagent (Thermo Fisher Scientific), according to the manufacturer's protocol. Cells were incubated for $24 \mathrm{~h}$ before collecting them for experiments. The cells were then washed with $1 \mathrm{~mL}$ PBS, sonicated in an ice bath, and placed in TRIzol reagent (Life Technologies) for mRNA extraction and real-time RT-PCR analyses (see above).

\section{Intravitreal Injection of KCL}

Six-week-old C57BL/6 male mice (CLEA Japan, Tokyo, Japan) were anesthetized with intraperitoneal injection of combined anesthetics \{midazolam $4 \mathrm{mg} / \mathrm{kg}$ BW (Sandoz 
Japan, Tokyo, Japan), medetomidine $0.75 \mathrm{mg} / \mathrm{kg}$ BW (Nippon Zenyaku Kogyo Co., Ltd., Fukushima, Japan), butorphanol tartrate $5 \mathrm{mg} / \mathrm{kg}$ BW (Meiji Seika Pharma Co., Ltd., Tokyo, Japan)]; their pupils were dilated using a single drop of a mixture of tropicamide and phenylephrine (0.5\% each; Mydrin-P®; Santen Pharmaceutical Co., Ltd., Osaka Japan) and received $2-\mu \mathrm{L}$ intravitreal injections of either KCL dissolved in PBS (50 mM) or just PBS as vehicle via an UltraMicroPump (type UMP2) equipped with a MicroSyringe Pump Controller (World Precision Instruments, Sarasota, FL) [31]. Twelve animals were used in each group.

\section{Statistical Analysis}

All results are expressed as the mean \pm standard deviation. Student's $t$ test was used to assess the statistical significance of differences among the groups of animals or cell culture conditions, with $p<0.05$ regarded as significant.

\section{Results}

\section{AQP4 Localization at the Synaptic Area of the Retina}

AQP4 was coexpressed with GS, a Müller glial cell marker, in the retina of WT mice (Fig. 1a). Müller glial cells span the entire thickness of the neural retina [25], and AQP4 was abundantly observed in the inner layer. In addition, AQP4 expression was also observed in the outer plexiform layer (OPL) where photoreceptor-bipolar synapses are distributed. Double immunostaining with the synaptic markers' synaptophysin (Fig. 1b, b'), PSD95 (Fig. 1c, c'), and bassoon (Fig. 1d, d') showed no colocalization with AQP4. In particular, bassoon signals were surrounded by AQP4 signal (Fig. 1d, d'), suggesting that AQP4 is localized in Müller glial cells surrounding the synapses between photoreceptor and bipolar cells.

\section{Visual Function Hyperactivity in Aqp4 KO Mice}

The visual function of Aqp $4 \mathrm{KO}$ mice was recorded by scotopic and photopic ERGs. In general, the a-wave represents photoreceptor function, while the b-wave shows the postsynaptic inner retinal function transferred from photoreceptor activity. We found that b-wave amplitude was higher in 12week-old KO mice than in WT mice of the same age (WT and KO; $n=5,5 ; p<0.05 ;$ Fig. 2a-e, Supplementary Table 1), and moreover, a-wave and b-wave amplitudes were also higher in KO than in WT mice at 16 weeks of age $(n=4,5$; $p<0.05$ and $p<0.01$, respectively; Fig. $2 \mathrm{f}-\mathrm{j}$, Supplementary Table 1). No change was observed in 8 -week-old mice (data not shown). Photopic ERG also showed an increase in b-wave

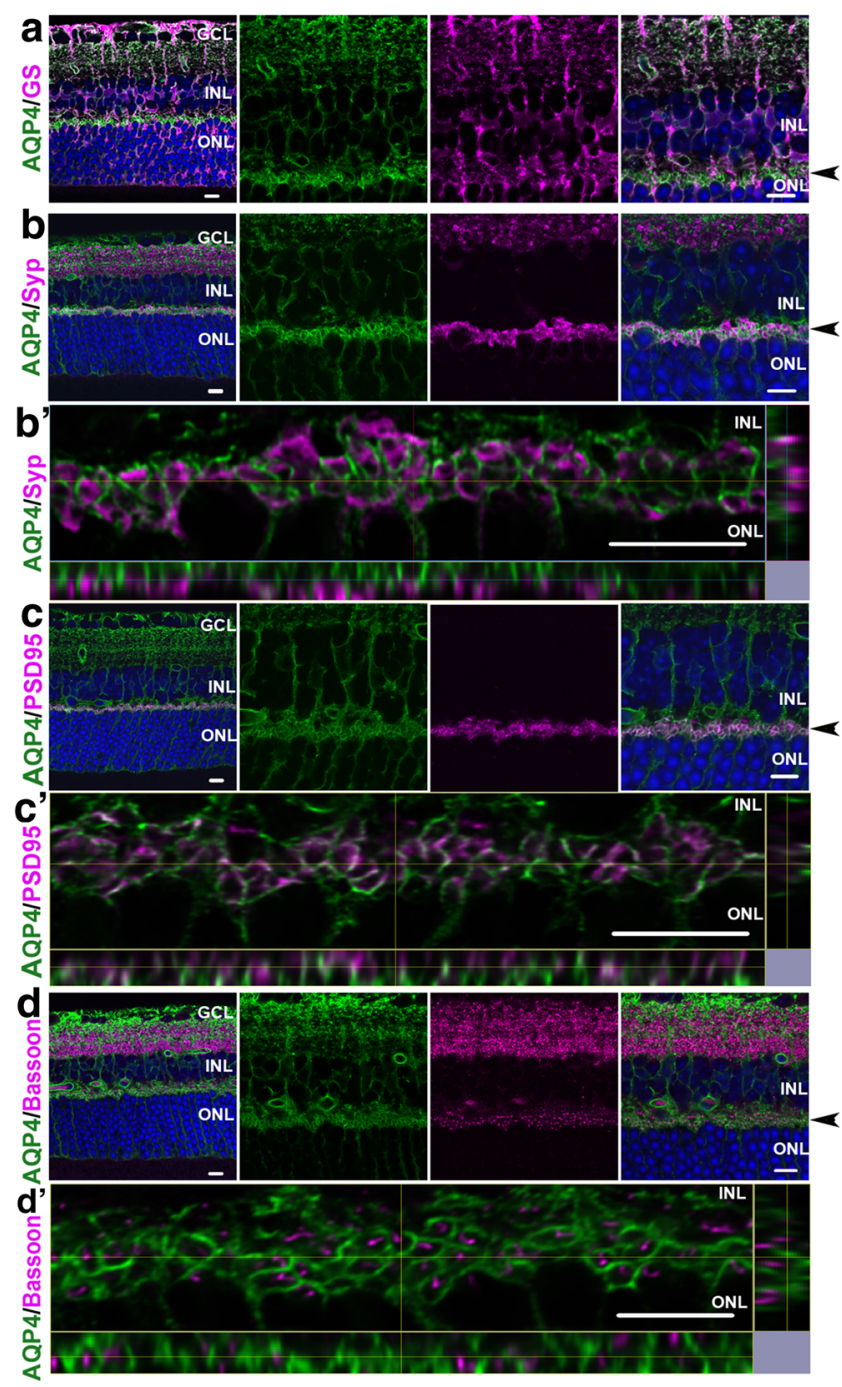

Fig. 1 AQP4 localization at the synaptic area of the mouse retina. a-d Wild-type retinal sections immunostained with AQP4 and glutamine synthetase (GS; a), synaptophysin (Syp; b, b'), PSD95 (c, c'), or bassoon $\left(d, d^{\prime}\right)$. Arrowheads show the outer plexiform layer (OPL) where photoreceptor-bipolar synapses are distributed. $\mathrm{b}^{\prime}, \mathrm{c}^{\prime}$, and $\mathrm{d}^{\prime}$ are magnifications of $b$, c, and d, respectively. AQP4 is coexpressed with GS but not with Syp, PSD95, or bassoon. Bassoon signals are surrounded by AQP4 $\left(\mathrm{d}, \mathrm{d}^{\prime}\right) . n=8$. GCL ganglion cell layer, INL inner nuclear layer, ONL outer nuclear layer. Scale bars, $10 \mu \mathrm{m}$

amplitude in 16-week-old $\mathrm{KO}$ mice compared with that in WT mice $(n=4,5 ; p<0.05$; Fig. 2k-m, Supplementary Table 1$)$. There were no changes in the implicit time of each recording. Meanwhile, there were no obvious histological changes including retinal thickness in Aqp4 KO mice (data not shown).

\section{Decrement of Visual Responses After Repeated Stimuli in Aqp4 KO Mice}

To elucidate whether Aqp4 deficiency could affect the recovery of synaptic homeostasis in retinal neurons of Aqp4 KO mice, ERG responses were recorded using flicker stimuli 
Fig. 2 Visual function hyperactivity in Aqp 4 knockout (KO) mice. Electroretinogram responses in wild-type (WT) and Aqp $4 \mathrm{KO}$ mice at $12(\mathbf{a}-\mathbf{e})$ and 16 (f-m) weeks of age. Scotopic (aj) and photopic $(\mathbf{k}-\mathbf{m})$ responses. Representative wave forms from an individual mouse $(\mathbf{a}, \mathbf{f}, \mathbf{k})$ and mean data of a-wave $(\mathbf{b}, \mathbf{d}, \mathbf{g}, \mathbf{i})$ and b-wave (c, e, $\mathbf{h}, \mathbf{j}, \mathbf{l}, \mathbf{m})$ are shown. The scotopic b-wave amplitude is higher in Aqp $4 \mathrm{KO}$ mice than in WT mice both at 12 (c) and 16 (h) weeks of age, while the scotopic a-wave (g) and photopic b-wave (I) amplitudes are higher in Aqp4 KO than WT mice at 16 weeks of age. There are no changes in the implicit time (d, e, $\mathbf{i}, \mathbf{j}, \mathbf{m})$. Twelve-week-old mice, $n=5$ (WT) and 5 (KO); 16-weekold mice, $n=4$ (WT) and 5 (KO). $* p<0.05$
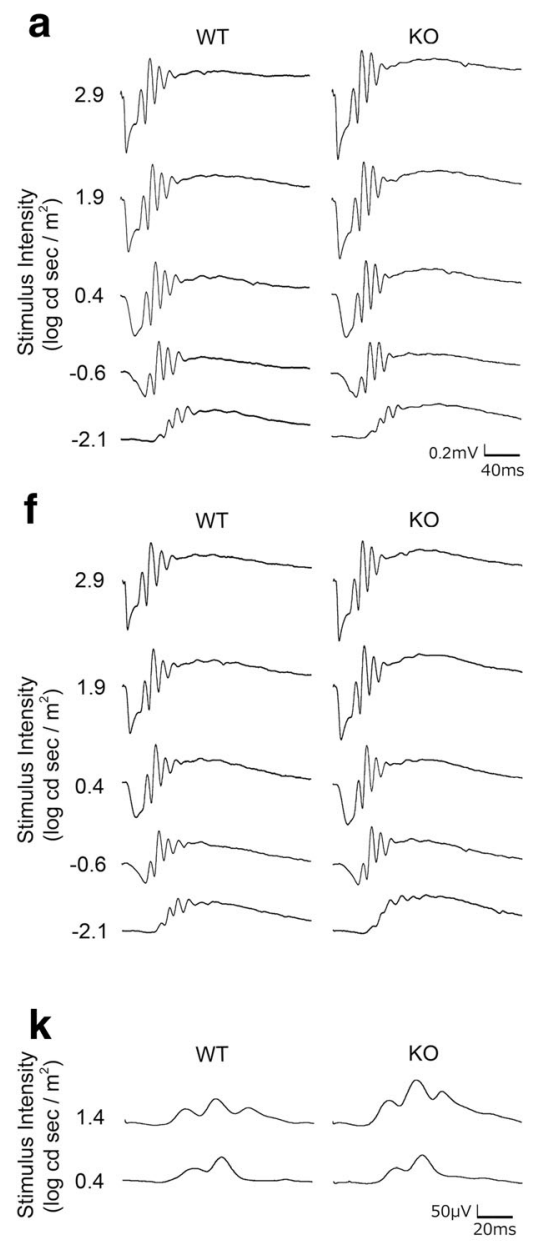
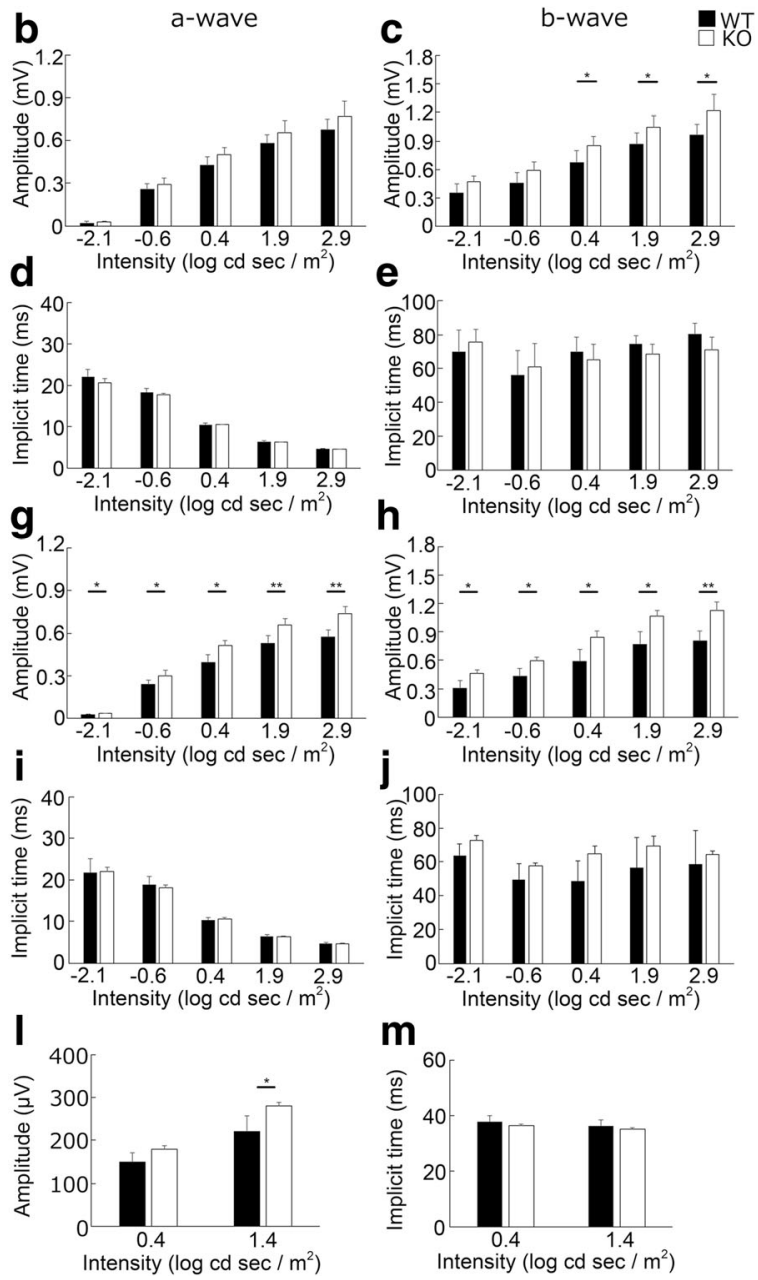

(Fig. 3a-h). The ratio of the scotopic ERG b-wave amplitude at the 20th stimulus to that of the first stimulus of $0.5 \mathrm{~Hz}$ was smaller in KO than in WT mice both at 10 weeks (WT $0.80 \pm$ $0.03, n=5$, and KO $0.71 \pm 0.07, n=6 ; p=0.023$; Fig. 3a, b) and at 12 weeks of age (WT $0.95 \pm 0.14, n=4$; KO $0.73 \pm$ $0.05, n=6 ; p=0.042$; Fig. 3e, f). The latter was also true for $1-$ Hz stimuli (WT $0.84 \pm 0.15, n=4$; KO $0.50 \pm 0.09, n=6 ; p=$ 0.013; Fig. 3g, h), indicating a greater decrement in Aqp $4 \mathrm{KO}$ mice after repeated stimuli. These data suggested that the electrical potential of neurons may not return to the appropriate resting potential after firing due to the insufficient clearance of synaptic mediators in Aqp $4 \mathrm{KO}$ mice.

\section{Alterations in mRNA Levels Related to Synaptic Transmission in the Retina of Aqp4 KO Mice}

The levels of functional molecules related to synaptic transmission were measured by real-time PCR in the retina of Aqp 4 KO mice. Significantly lower levels of $G s$ (WT and KO, $n=7$, $9 ; p=0.046$; Fig. 4a) and Glast ( $n=9,10 ; p=0.029$; Fig. 4b), which are expressed in Müller glial cells and contribute to neurotransmitter metabolism and transfer, respectively, were found in the retina of Aqp $4 \mathrm{KO}$ than of WT mice at 16 weeks of age. The presynaptic molecule synaptophysin was also downregulated in $\mathrm{KO}$ mice ( $n=5,5 ; p=0.036$; Fig. 4c).

At the synaptic area, potassium channels are gated by intracellular calcium elevation and are associated with synaptic plasticity [32]. The extracellular potassium released by excitatory neurons is buffered by glial cells in the brain [33]. Real-time PCR analysis showed that the mRNA levels of one of the strongly rectifying inward potassium channels, Kir2.1 [32, 34], was downregulated in the neural retinal tissue of Aqp4 $\mathrm{KO}$ mice $(n=9,9 ; p=$ 0.000 ; Fig. 4d). In contrast, the mRNA expression of Kir4.1, a weakly rectifying channel acting both as an inward and outward channel [32, 34] $(n=5,5 ; p=0.990$; Fig. 4e); $K c n v 2$, a voltage-gated potassium channel subunit expressed in photoreceptor cells [35] $(n=5,5 ; p=0.917$; Fig. 4f); and Surl ( $n=5,5 ; p=0.379$, data not shown) and TASK-1 ( $n=5,5 ; p=0.828$, data not shown), two potassium channels both of which are found in the retina [36], was not changed by Aqp4 deletion. 

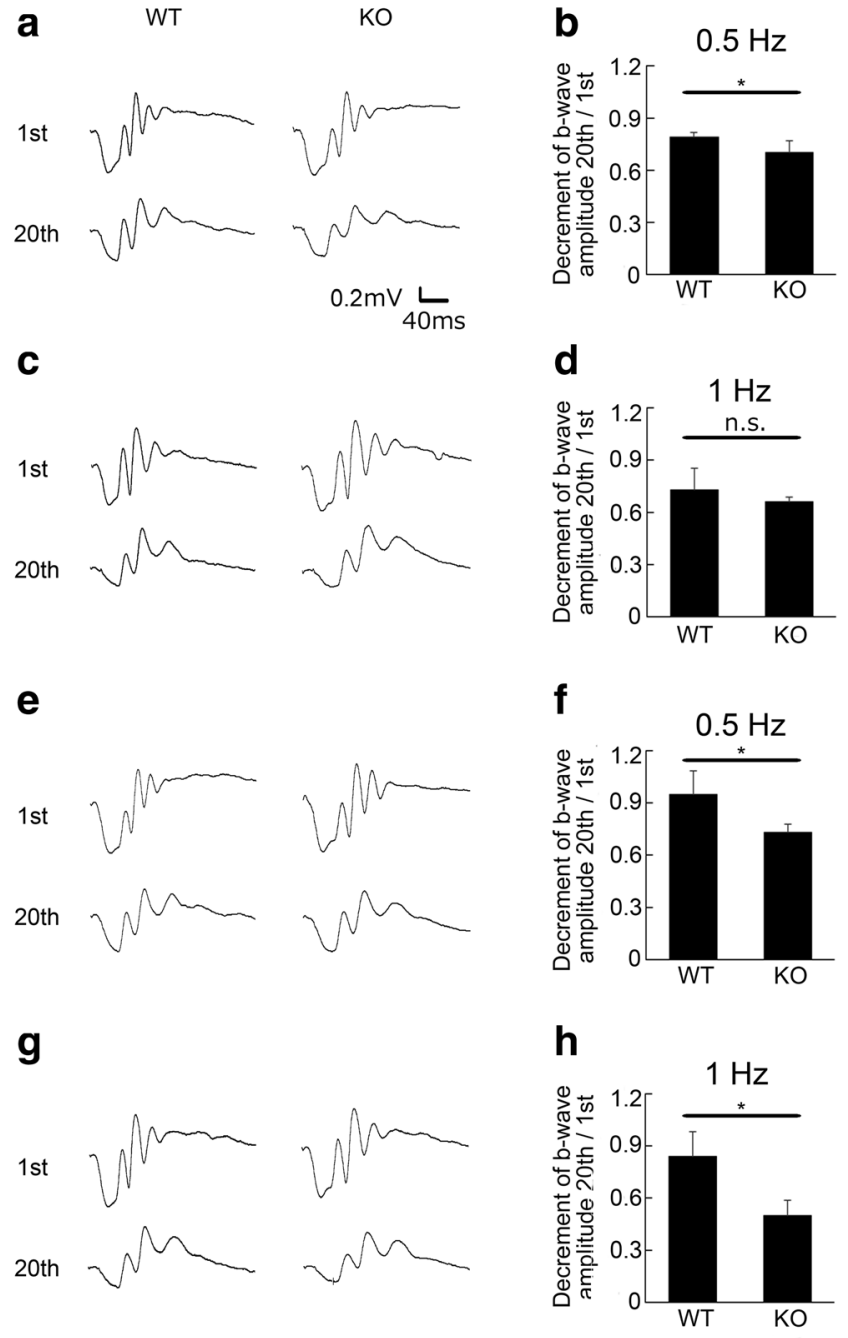

Fig. 3 Decrement of visual responses after repeated stimuli in Aqp4 knockout $(\mathrm{KO})$ mice. Scotopic electroretinogram responses using flicker stimuli from wild-type (WT) and Aqp4 KO mice at 10 (a-d) and $12(\mathbf{e}-\mathbf{h})$ weeks of age. Mice were stimulated with $0.5-\mathrm{Hz}(\mathbf{a}, \mathbf{b}, \mathbf{e}, \mathbf{f})$ or $1-$ $\mathrm{Hz}(\mathbf{c}, \mathbf{d}, \mathbf{g}, \mathbf{h})$ flicker light. Representative wave forms from an individual mouse (a, $\mathbf{c}, \mathbf{e}, \mathbf{g})$ and the mean b-wave amplitude ratio of the 20th to the 1 st stimulus ( $\mathbf{b}, \mathbf{d}, \mathbf{g}, \mathbf{i})$ are shown. The ratio is smaller in Aqp $4 \mathrm{KO}$ than WT mice at 10 weeks of age with $0.5-\mathrm{Hz}$ stimuli $(\mathbf{a}, \mathbf{b})$ and at 12 weeks with $0.5-\mathrm{Hz}(\mathbf{e}, \mathbf{f})$ and $1-\mathrm{Hz}$ stimuli $(\mathbf{g}, \mathbf{h})$. Ten-week-old mice, $n=5$ (WT) and $6(\mathrm{KO}) ; 12$-week-old mice, $n=4(\mathrm{WT})$ and $6(\mathrm{KO}) . * p<0.05$

\section{Kir2.1 Downregulation in Müller Glial Cells upon Aqp4 Deletion}

Double immunohistochemistry showed that KIR2.1 localized in GS-positive Müller glial cells (Fig. 5a, a'). Meanwhile, KIR2.1 did not colocalize with synaptophysin expressed by neuronal cells in the OPL (Fig. 5b, b'). To examine whether Kir2.1 expression is affected by Aqp 4 deletion in Müller glial cells, we used a primary culture system. In cultured Müller glial cells, Aqp4 knockdown (KD), confirmed by real-time PCR (control and $\mathrm{KD}, n=4,5$; $p=0.002$; Fig. 5c), resulted in downregulation of Kir2.1
mRNA levels ( $n=4,5 ; p=0.000$; Fig. 5 d), but not of Kir4.1 ( $n=4,5 ; p=0.444$; Fig. 5e), suggesting that Kir2.1 and not Kir4.1 levels are affected by Aqp 4 deletion in Müller glial cells.

\section{Modulation of Intraocular Potassium Levels Induces Hyperactive Visual Function in Aqp4 KO Mice}

Since KIR2.1 acts as an inward potassium channel, its downregulation and the subsequent increase in extracellular potassium levels may be associated with the hyperactivity of visual responses observed in $\mathrm{KO}$ mice. To further examine this, we intraocularly injected $\mathrm{KCl}$ and measured photopic ERG; for technical reasons, we could not measure scotopic ERG, as it requires dark adaptation, and the injection needed to be done under bright light. The amplitude of photopic ERG stimulated by $1.4 \log \mathrm{cd} \mathrm{s} / \mathrm{m}^{2}$ increased after potassium loading, in a similar manner as after Aqp4 deletion in mice (vehicle $65.24 \pm 20.33 \mathrm{mV}$; KCL $92.81 \pm 26.99 \mathrm{mV} ; n=12, p=$ 0.010; Fig. 5f, g). The implicit time was not changed (Fig. 5f, h).

\section{Mitochondria Changes in the Retina of Aqp4 KO Mice}

In contrast to the increased ERG responses, the expression of functional molecules in Müller glial cells and neurons was decreased, as shown above. We next analyzed the mRNA levels of mitochondria-related molecules. Mitochondria constitute the energy supplier of the cells, and the retina is an energy-demanding tissue due to high neuronal activity [37, 38]. In the retina of Aqp $4 \mathrm{KO}$ mice at 16 weeks of age, we found a significant downregulation of the mRNA levels of Pgcla, an indispensable molecule for mitochondria biogenesis (WT and KO, $n=7,9 ; p=0.018$; Fig. 6a), and $\operatorname{CoxIV}(n=5$, $5 ; p=0.022$; Fig. 6b) and $C y t C(n=8,10 ; p=0.024$; Fig. 6c), two mitochondrial respiratory enzymes, compared with the respective levels in the retina of WT mice. Meanwhile, the levels of $\mathrm{Ho}-1$, an antioxidative molecule induced by oxidative stress and related to respiratory responses in mitochondria to resolve the stress, were not changed $(n=8,10 ; p=0.610$; Fig. $6 \mathrm{~d})$, suggesting no increase in oxidative stress. In addition, the levels of Fis 1 ( $n=9,10 ; p=0.002$; Fig. 6e), Mfn $1(n=$ 7, 9; $p=0.008$; Fig. 6f), and $M f n 2(n=9,10 ; p=0.020$; Fig. $6 \mathrm{~g}$ ), which are induced during mitochondria remodeling to eliminate pathological mitochondria, were reduced. In contrast, the apoptosis checkpoint family molecules, $\operatorname{Bcl} 2(n=8,10 ; p=0.042$; Fig. $6 \mathrm{~h})$ and $\operatorname{Bax}(n=$ 8,$10 ; p=0.025$; Fig. 6i) were upregulated, suggesting that mitochondria homeostasis is disorganized in the retina of Aqp4 KO mice. 
Fig. 4 Alteration in mRNA levels related to synaptic transmission in the retina of Aqp4 knockout (KO) mice. Real-time RT-PCR in retinal samples derived from wildtype (WT) and Aqp $4 \mathrm{KO}$ mice at 16 weeks of age $(\mathbf{a}-\mathbf{f})$. The relative mRNA levels of glutamine synthetase (Gs; a), glutamate aspartate transporter (Glast; b), synaptophysin $(S y p ; \mathbf{c})$, and Kir2.1 (d) are downregulated in the retina of Aqp $4 \mathrm{KO}$ mice, compared with the respective levels in WT retinas. The levels of Kir4.1 (e) and Kcnv2 (f) are not changed. $n=5-10 . * p<0.05$
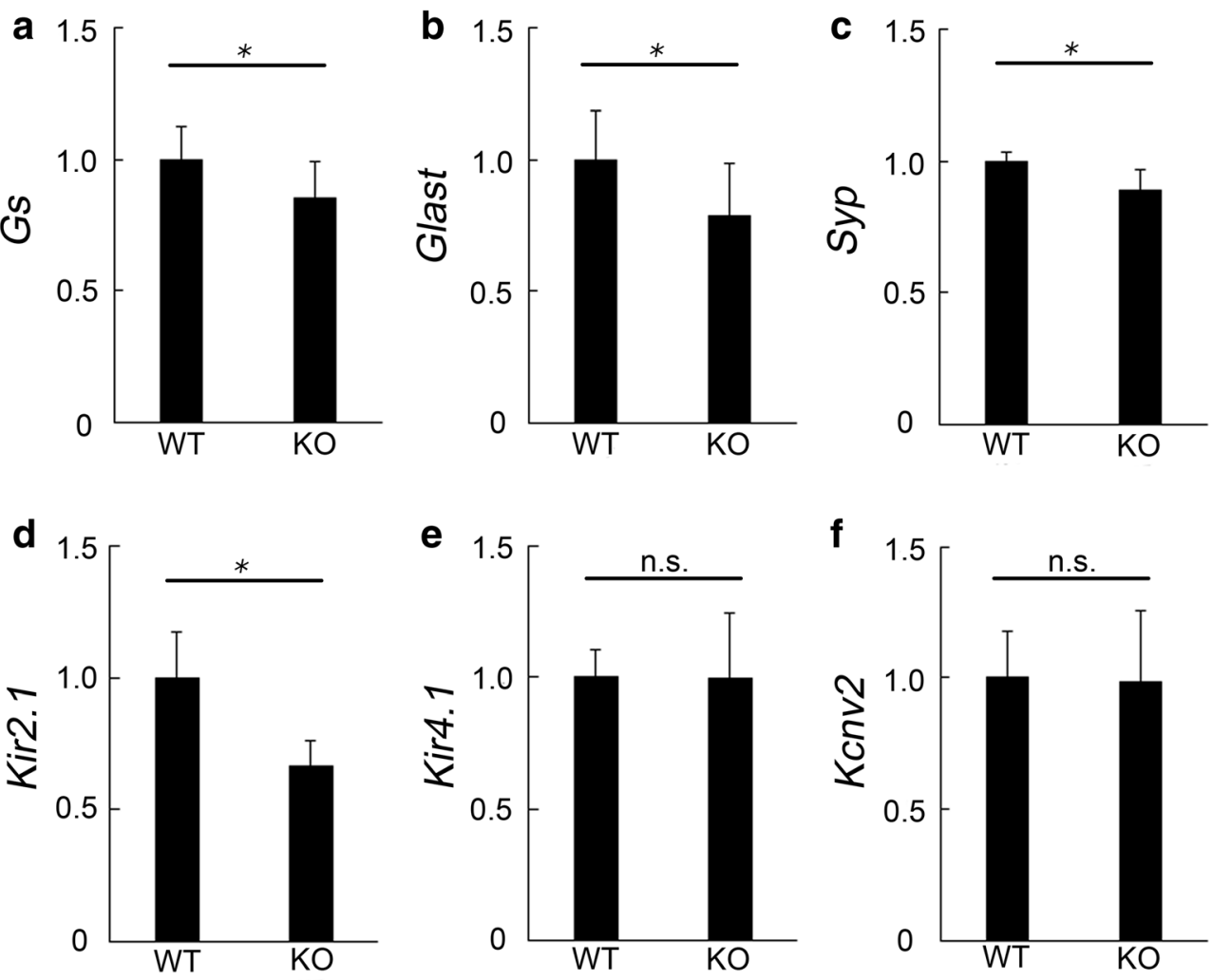

\section{Discussion}

In this study, we demonstrated that AQP4 is expressed in Müller glial cells at the synaptic area between photoreceptors and bipolar cells, which compose the OPL. Compared with WT mice, Aqp4 KO mice displayed hyperactive visual function, which gradually progressed with age. The decrement in b-wave amplitudes after repeated stimuli was also greater in Aqp4 KO mice. Functional molecules related to synaptic transmission were downregulated in $\mathrm{KO}$ retinas. In addition, KIR2.1, an inward potassium channel, expressed at the synaptic area in Müller glial cells, was also downregulated, while increased extracellular potassium levels in WT mice recapitulated the hyperactive photopic ERG responses in $\mathrm{KO}$ animals. In Aqp $4 \mathrm{KO}$ retinas, molecules related to mitochondria biogenesis, respiration, and remodeling were downregulated, whereas apoptotic markers were upregulated.

The presence of AQP4 in Müller glial cells shown by immunostaining is consistent with a previous report using immune electron microscopy images [24]. This study found that AQP4 is concentrated at the perivascular end feet of Müller glial cells. Additionally, we observed that AQP4 is also distributed around, but not colocalized with, neuronal synapses between photoreceptor and bipolar cells.

Aqp $4 \mathrm{KO}$ mice did not show obvious histological abnormalities at the analyzed ages (data not shown), consistently with previous reports [9]; however, they exhibited a clear phenotype in visual responses recorded by ERG. KO mice showed hyperactivity both in scotopic and photopic ERGs, which reflect rod and cone photoreceptor pathways functioning under dark and light conditions, respectively. Moreover, the repeated light-evoked synaptic stimuli caused weakening of visual responses in Aqp $4 \mathrm{KO}$ mice. A similar fatigue phenomenon in response to repeated stimuli is observed in myasthenia gravis [39], where the autoimmune system alters the neurotransmitter refractory period in the neuromuscular junction. These findings support the idea that Aqp4 deficiency causes a disorganization in the kinetics of neurotransmitters.

Extracellular potassium is known to be critical in defining the membrane potential of neurons [25]. Previous reports have shown that light-evoked increases in extracellular potassium in the OPL cause hyperactive ERG responses [40], while increased ERG amplitudes are also observed after injection of tetraethylammonium chloride, a blocker of potassium rectifiers [41]. We found that Aqp4 KO mice show repression of Kir2.1, an inward potassium channel in the retina, and a previous report indicated increased extracellular potassium ion levels in the brain of Aqp $4 \mathrm{KO}$ mice [42], suggesting that potassium ions may be also increased in $\mathrm{KO}$ retinas. Moreover, we showed that intraocular injection of KCL increased the ERG amplitude, similarly to Aqp4 deletion in mice, supporting that hyperactive ERG responses observed in Aqp4 KO mice would, at least in part, be induced by the increased extracellular potassium ion levels in the retina.

Insufficient KIR4.1 action, most likely by its redistribution, which is related to Aqp 4 deficiency, was reported to affect 
Fig. 5 Modulation of intraocular potassium levels induces hyperactive photopic electroretinogram (ERG) responses in mice. a, b Double immunohistostaining for KIR2.1 and glutamine synthetase (GS; a, $\left.a^{\prime}\right)$ or synaptophysin (Syp; b, b') in wild-type (WT) retinal sections. $\mathrm{a}^{\prime}$ and $\mathrm{b}^{\prime}$ are magnifications of $a$ and $b$, respectively. GS ( $a, a^{\prime}$; arrows) but not Syp (b, b') colocalizes with KIR2.1. Arrowheads show the outer plexiform layer. $n=8$. GCL ganglion cell layer, INL inner nuclear layer, ONL outer nuclear layer. Scale bar, $10 \mu \mathrm{m}$. c-e Real-time RT-PCR of primary Müller glial cell culture samples transfected with control (si-cont) or Aqp4 siRNA (siAQP4). Quantification of the relative mRNA levels confirms the knockdown (KD) of Aqp4 (c). Kir2.1 (d) but not Kir4.1 (e) is downregulated in Müller glial cells. $n=4$ (control) and 5 (KD). $\mathrm{f}-\mathrm{h}$ Photopic ERGs after intraocular injection of vehicle (PBS) or $\mathrm{KCL}$. The b-wave amplitude is increased by the potassium load (f, $g$ ). The implicit time is not changed $(\mathrm{H}) . n=12$ for each group; $* p<0.05 ; * * p<0.01$

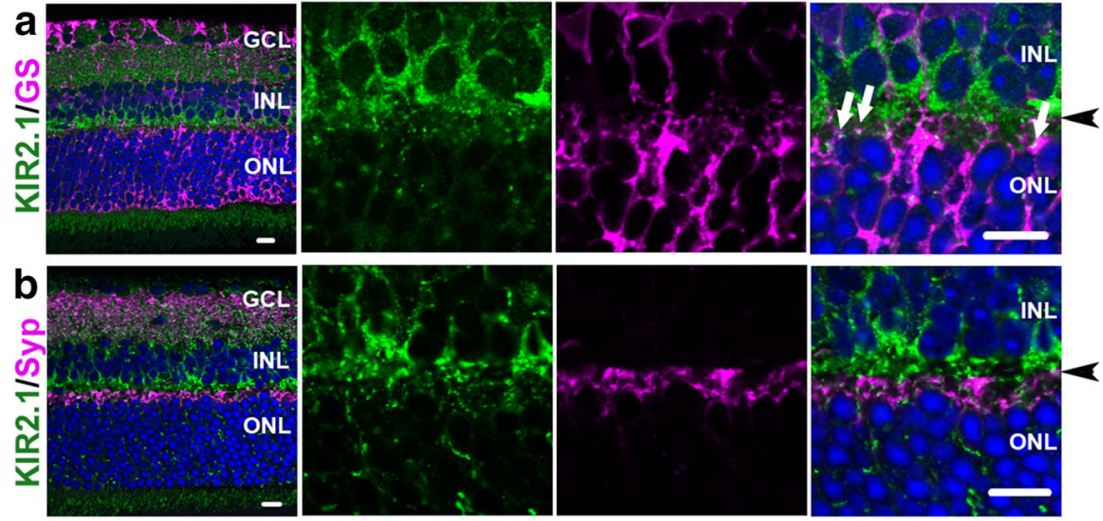

C

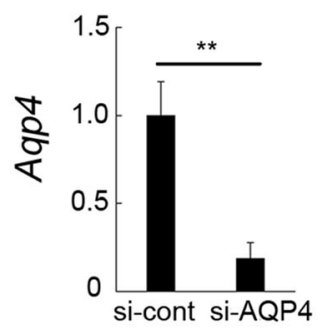

f

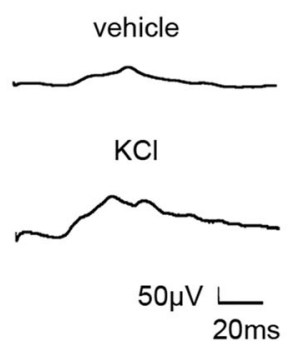

d

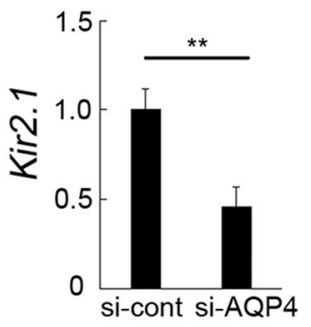

g

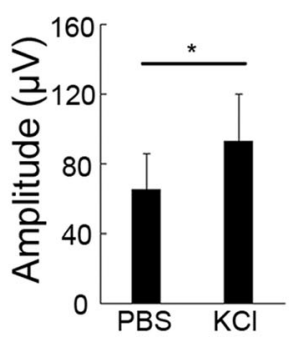

e

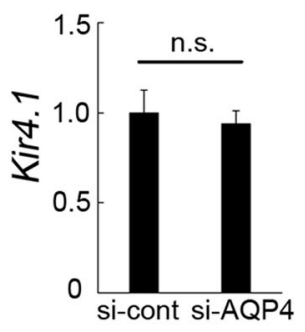

h

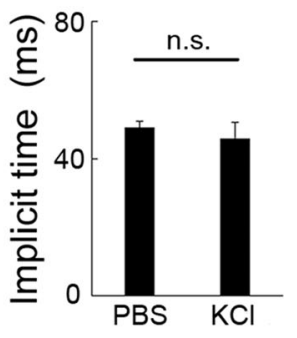

osmotic condition in Müller glial cells [43-45]. KIR4.1 is expressed in the membranes of Müller glial cells surrounding the retinal vessels, the end feet facing the vitreous cavity, and within the nerve fiber layer, but not at the synaptic site, which was reported previously [32, 46]. In addition, KIR4.1 levels are affected by vascular diseases, such as ischemia [24] and diabetes [34], and have a major role in regulating the bloodretina barrier [19]. In the current study, we found that the mRNA levels of Kir2.1 are downregulated in Aqp4 KO retinas and Aqp4-deficient Müller glial cells in vitro and that the protein is distributed around synapses in the mouse retina. While KIR 2.1 was previously reported to be present in Müller glial cells and, most likely, neurons of the inner nuclear layer in the retina [32], in contrast to the brain where it is expressed in neurons rather than glia [47], its localization to the synaptic area had not been clarified. Our present study showed that KIR 2.1 can be found in Müller glial cells at the synaptic area, but not in the synapses of neuronal cells in the retina, as shown by high-magnification images. Therefore, potassium homeostasis at the synaptic area is at least in part regulated by AQP4-KIR2.1 interaction, although we cannot exclude the possibility that other potassium channels may be involved in synaptic activity, in collaboration with AQP4.

Extracellular potassium ion levels affect electrogenic glutamate uptake [48]. We found that Glast is repressed in Aqp4 $\mathrm{KO}$ retinas; this transporter in Müller glial cells uptakes the extracellular glutamate around photoreceptor cells and is required for glutamate recycling and preserving normal glutamate levels at the synaptic cleft between photoreceptors and bipolar cells [49]. Given that the mice showed hyperactive ERG responses, glutamate may have been accumulated in the synaptic cleft. Further, Müller glial cells not only prevent the diffusion of glutamate released by photoreceptor cells out of the synaptic cleft and glutamate uptake but also supply neurons with glutamine and neurotransmitter precursors, such as GABA [50, 51]. Aqp4 $\mathrm{KO}$ mice exhibited lower levels of $G s$, an enzyme that converts glutamate into glutamine, a source of GABA; visual hyperactivity observed in the $\mathrm{KO}$ 
Fig. 6 Mitochondria changes in the retina of Aqp 4 knockout (KO) mice. Real-time RT-PCR in retinal samples derived from wildtype (WT) and Aqp $4 \mathrm{KO}$ mice at 16 weeks of age $(\mathbf{a}-\mathbf{i})$. The relative mRNA levels of $P g c l \alpha$ (a), $\operatorname{CoxIV}$ (b), CytC (c), Fisl (e), $M f n 1$ (f), and $M f n 2(\mathbf{g})$ are downregulated in Aqp4 $\mathrm{KO}$ retinas, while $\mathrm{Ho}-\mathrm{l}$ (d) levels are not changed, compared with the respective levels in WT mice. The mRNA levels of $B c l 2$ (h) and $B a x$ (i) are higher in Aqp4 $\mathrm{KO}$ than in WT retina. $n=5-10 . * p<0.05$; $* * p<0.01$ a

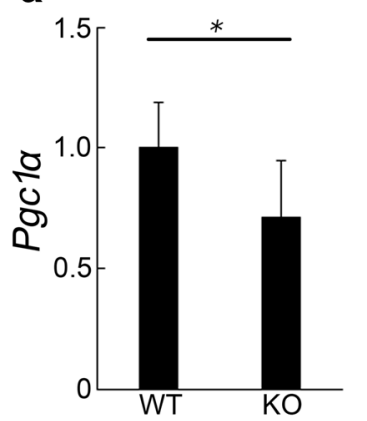

b

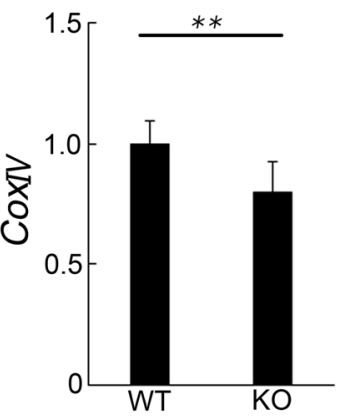

C

d

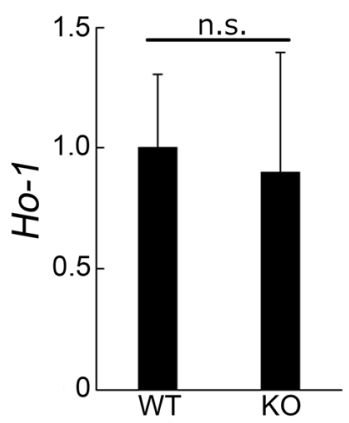

e

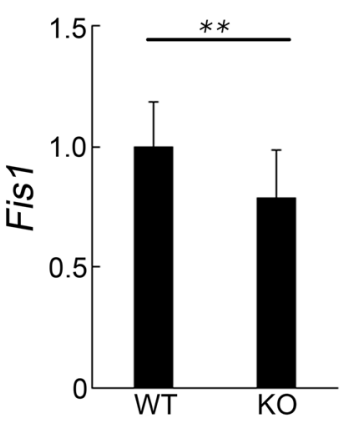

g

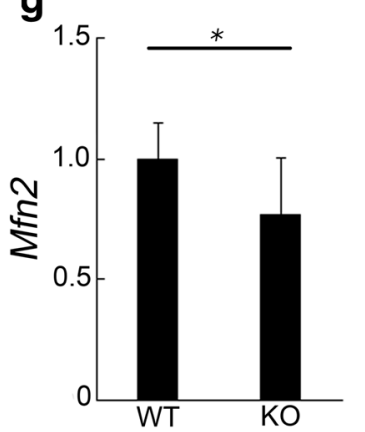

h

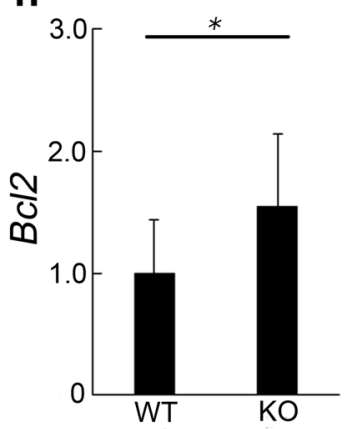

f
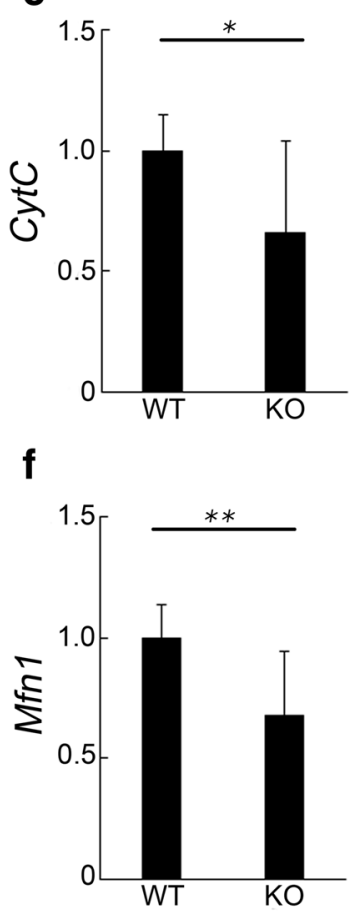

i

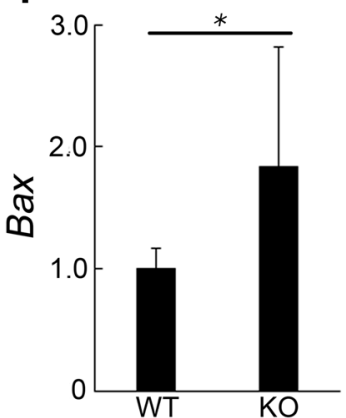

mice may have involved the influence of GABA levels [52]. In addition, synaptic fatigue during repeated stimulation may be related to the insufficient clearance of glutamate at the synaptic area. Thus, Aqp $4 \mathrm{KO}$ mice may have an imbalance in neurotransmitter metabolism. Regarding the a-wave derived from photoreceptor cells in scotopic ERG, the accumulated glutamate at the synaptic cleft during dark may have caused excessive depolarization of photoreceptor cells, thus resulting in an apparently greater amplitude at the time of the light stimulus.

Hyperactivity is observed at the time of synaptic remodeling related to local neurodegenerative changes [52]. While Aqp $4 \mathrm{KO}$ mice show reduction in visual function at 40 weeks of age, as previously reported [26], the changes in the visual responses of the Aqp $4 \mathrm{KO}$ mice at 12 and 16 weeks old were not the reduction but the hyperactivity and synaptic fatigue; these changes would have represented the early changes of the neural disorder. Neural hyperactivity is also observed at the early stage of Alzheimer's disease, a neural disorder [53, 54]. Given that abnormal clearance of synaptic glutamate by Müller glial cells causes neurotoxicity [50, 55-58], and apoptotic markers were increased in Aqp4 KO retinas, synaptic disorder and postsynaptic remodeling may have already occurred at least by 16 weeks of age, and thus synaptophysin expression was changed. The fact that neural hyperactivity precedes neurodegeneration is a common finding in Alzheimer's disease and Aqp4 deficiency. Thus, the current study may help understand the mechanism underlying Alzheimer's disease [22].

Another similarity to Alzheimer's disease involves mitochondria changes. Mitochondrial dysfunction in the brains of patients with Alzheimer's disease correlates with a wide range of mitochondrial abnormalities. One hypothesis regarding such secondary abnormalities is that mitochondria aging is accelerated by neural hyperactivity, which further induces mitochondria exhaustion [59], given that synaptic transmission 
is regulated by mitochondria through modulating ATP production [60]. Moreover, dysregulation of mitochondria fission-fusion balance promotes neurodegeneration [61], and $P g c l \alpha \mathrm{KO}$ mice show hyperactivity [62]. In the retina of Aqp $4 \mathrm{KO}$ mice, fission-fusion markers and $P g c l \alpha$ were downregulated, which may have accelerated neurodegeneration in these mice. Therefore, a vicious cycle of hyperactivity and mitochondria disorganization might explain the pathogenesis of Aqp $4 \mathrm{KO}$ mice and the age-related progression, leading to the induction of mitochondria-related apoptotic markers, like Bcl 2 family molecules, in the retina of Aqp $4 \mathrm{KO}$ mice.

In humans, hyperactivity in ERG responses is observed in central retinal vein occlusion [63], and the estimated mechanism involves ischemia-related increase in the local levels of inflammatory cytokines [64]. Given that AQP4 is important for water diffusion allowing bidirectional water transport across the plasma membrane [3, 12], the fine-tuning of diffusible factor concentrations, besides glutamate and potassium, at the neuron-glial site could be also involved in its role in preserving neuron-microenvironment homeostasis. Thus, multiple systems may be dysregulated in Aqp4 KO retinas.

In summary, we demonstrated that neural hyperactivity and synaptic fatigue in Aqp $4 \mathrm{KO}$ mice occur before neurodegeneration becomes evident. Moreover, we showed that Aqp4 deficiency disturbs synaptic homeostasis and mitochondria metabolism most likely through dysregulation of potassium metabolism and possibly through glutamate kinetics. Our results suggest that the bidirectional water channel AQP4 is important for adjusting the levels of extracellular factors secreted upon neuronal firing and fine-tuning neurotransmission to regulate neural and visual activity.

Acknowledgements We thank all the members of Laboratory of Retinal Cell Biology (RCB lab) for kind assistance, Dr. Kaoru Fujinami, an alumnus of RCB lab, for kindly advising the evaluation of ERG records, and the members of Department of Pharmacology for assisting the animal breeding.

Funding This study was funded partly by a grant-in-aid for Scientific Research to Y.O. by Japan Society of the Promotion of Science.

\section{Compliance with Ethical Standards}

Ethical Approval All procedures performed in studies involving animals were in accordance with the ethical standards of the ARVO Statement for the Use of Animals in Ophthalmic and Vision Research and the guidelines of the Animal Care Committee of Keio University.

Open Access This article is distributed under the terms of the Creative Commons Attribution 4.0 International License (http:// creativecommons.org/licenses/by/4.0/), which permits unrestricted use, distribution, and reproduction in any medium, provided you give appropriate credit to the original author(s) and the source, provide a link to the Creative Commons license, and indicate if changes were made.

\section{References}

1. Agre P, Preston GM, Smith BL, Jung JS, Raina S, Moon C, Guggino WB, Nielsen S (1993) Aquaporin CHIP: the archetypal molecular water channel. Am J Phys 265(4 Pt 2):F463-F476. https://doi.org/10.1152/ajprenal.1993.265.4.F463

2. Brown D (2017) The discovery of water channels (aquaporins). Ann Nutr Metab 70(Suppl 1):37-42. https://doi.org/10.1159/ 000463061

3. Yu YC, Sohma Y, Takimoto S, Miyauchi T, Yasui M (2013) Direct visualization and quantitative analysis of water diffusion in complex biological tissues using CARS microscopy. Sci Rep 3:2745. https://doi.org/10.1038/srep02745

4. Watanabe-Matsumoto S, Moriwaki Y, Okuda T, Ohara S, Yamanaka K, Abe Y, Yasui M, Misawa H (2018) Dissociation of blood-brain barrier disruption and disease manifestation in an aquaporin-4-deficient mouse model of amyotrophic lateral sclerosis. Neurosci Res 133:48-57. https://doi.org/10.1016/j.neures. 2017.11.001

5. Ikeshima-Kataoka H, Abe Y, Abe T, Yasui M (2013) Immunological function of aquaporin-4 in stab-wounded mouse brain in concert with a pro-inflammatory cytokine inducer, osteopontin. Mol Cell Neurosci 56:65-75. https://doi.org/10.1016/j. men.2013.02.002

6. Li XM, Wendu RL, Yao J, Ren Y, Zhao YX, Cao GF, Qin J, Yan B (2014) Abnormal glutamate metabolism in the retina of aquaporin 4 (AQP4) knockout mice upon light damage. Neurol Sci 35(6):847853. https://doi.org/10.1007/s10072-013-1610-7

7. Jo AO, Ryskamp DA, Phuong TT, Verkman AS, Yarishkin O, MacAulay N, Krizaj D (2015) TRPV4 and AQP4 channels synergistically regulate cell volume and calcium homeostasis in retinal Muller glia. J Neurosci 35(39):13525-13537. https://doi.org/10. 1523/JNEUROSCI.1987-15.2015

8. Pisani F, Cammalleri M, Dal Monte M, Locri F, Mola MG, Nicchia GP, Frigeri A, Bagnoli P et al (2018) Potential role of the methylation of VEGF gene promoter in response to hypoxia in oxygeninduced retinopathy: beneficial effect of the absence of AQP4. J Cell Mol Med 22(1):613-627. https://doi.org/10.1111/jcmm.13348

9. Ma T, Yang B, Gillespie A, Carlson EJ, Epstein CJ, Verkman AS (1997) Generation and phenotype of a transgenic knockout mouse lacking the mercurial-insensitive water channel aquaporin-4. J Clin Invest 100(5):957-962. https://doi.org/10.1172/JCI231

10. Jung JS, Bhat RV, Preston GM, Guggino WB, Baraban JM, Agre P (1994) Molecular characterization of an aquaporin cDNA from brain: candidate osmoreceptor and regulator of water balance. Proc Natl Acad Sci U S A 91(26):13052-13056

11. Kozono D, Yasui M, King LS, Agre P (2002) Aquaporin water channels: atomic structure molecular dynamics meet clinical medicine. J Clin Invest 109(11):1395-1399. https://doi.org/10.1172/ JCI15851

12. Nagelhus EA, Ottersen OP (2013) Physiological roles of aquaporin-4 in brain. Physiol Rev 93(4):1543-1562. https:// doi.org/10.1152/physrev.00011.2013

13. Misu T, Fujihara K, Kakita A, Konno H, Nakamura M, Watanabe S, Takahashi T, Nakashima I et al (2007) Loss of aquaporin 4 in lesions of neuromyelitis optica: distinction from multiple sclerosis. Brain J Neurol 130 (Pt 5:1224-1234. https://doi.org/10.1093/brain/ awm047

14. Wingerchuk DM, Banwell B, Bennett JL, Cabre P, Carroll W, Chitnis T, de Seze J, Fujihara K et al (2015) International consensus diagnostic criteria for neuromyelitis optica spectrum disorders. Neurology 85(2):177-189. https://doi.org/10.1212/WNL. 0000000000001729

15. Kezuka T, Usui Y, Yamakawa N, Matsunaga Y, Matsuda R, Masuda M, Utsumi H, Tanaka K et al (2012) Relationship between 
NMO-antibody and anti-MOG antibody in optic neuritis. J Neuroophthalmol 32(2):107-110. https://doi.org/10.1097/WNO. $0 \mathrm{~b} 013 \mathrm{e} 31823 \mathrm{c} 9 \mathrm{~b} 6 \mathrm{c}$

16. Vujosevic S, Micera A, Bini S, Berton M, Esposito G, Midena E (2015) Aqueous humor biomarkers of Muller cell activation in diabetic eyes. Invest Ophthalmol Vis Sci 56(6):3913-3918. https://doi.org/10.1167/iovs.15-16554

17. Cui B, Sun JH, Xiang FF, Liu L, Li WJ (2012) Aquaporin 4 knockdown exacerbates streptozotocin-induced diabetic retinopathy through aggravating inflammatory response. Exp Eye Res 98:3743. https://doi.org/10.1016/j.exer.2012.02.013

18. Kumar B, Gupta SK, Nag TC, Srivastava S, Saxena R, Jha KA, Srinivasan BP (2014) Retinal neuroprotective effects of quercetin in streptozotocin-induced diabetic rats. Exp Eye Res 125:193-202. https://doi.org/10.1016/j.exer.2014.06.009

19. Zhang Y, Xu G, Ling Q, Da C (2011) Expression of aquaporin 4 and Kir4.1 in diabetic rat retina: treatment with minocycline. J Int Med Res 39(2):464-479. https://doi.org/ $10.1177 / 147323001103900214$

20. Jukkola P, Gu C (2015) Regulation of neurovascular coupling in autoimmunity to water and ion channels. Autoimmun Rev 14(3): 258-267. https://doi.org/10.1016/j.autrev.2014.11.010

21. Camassa LMA, Lunde LK, Hoddevik EH, Stensland M, Boldt HB, De Souza GA, Ottersen OP, Amiry-Moghaddam M (2015) Mechanisms underlying AQP4 accumulation in astrocyte endfeet. Glia 63(11):2073-2091. https://doi.org/10.1002/glia.22878

22. Lan YL, Zhao J, Ma T, Li S (2016) The potential roles of aquaporin 4 in Alzheimer's disease. Mol Neurobiol 53(8):5300-5309. https://doi.org/10.1007/s12035-015-9446-1

23. Haj-Yasein NN, Jensen V, Ostby I, Omholt SW, Voipio J, Kaila K, Ottersen OP, Hvalby O et al (2012) Aquaporin-4 regulates extracellular space volume dynamics during high-frequency synaptic stimulation: a gene deletion study in mouse hippocampus. Glia 60(6): 867-874. https://doi.org/10.1002/glia.22319

24. Iandiev I, Tenckhoff S, Pannicke T, Biedermann B, Hollborn M, Wiedemann P, Reichenbach A, Bringmann A (2006) Differential regulation of Kir4.1 and Kir2.1 expression in the ischemic rat retina. Neurosci Lett 396(2):97-101. https://doi.org/10.1016/j.neulet. 2005.11.016

25. Vecino E, Rodriguez FD, Ruzafa N, Pereiro X, Sharma SC (2016) Glia-neuron interactions in the mammalian retina. Prog Retin Eye Res 51:1-40. https://doi.org/10.1016/j.preteyeres.2015.06.003

26. Li J, Patil RV, Verkman AS (2002) Mildly abnormal retinal function in transgenic mice without Muller cell aquaporin-4 water channels. Invest Ophthalmol Vis Sci 43(2):573-579

27. Kato J, Takai Y, Hayashi MK, Kato Y, Tanaka M, Sohma Y, Abe Y, Yasui M (2014) Expression and localization of aquaporin-4 in sensory ganglia. Biochem Biophys Res Commun 451(4):562-567. https://doi.org/10.1016/j.bbrc.2014.08.026

28. Ramadhanti J, Huang P, Kusano-Arai O, Iwanari H, Sakihama T, Misu T, Fujihara K, Hamakubo T et al (2013) A novel monoclonal antibody against the $\mathrm{C}$-terminal region of aquaporin-4. Monoclon Antib Immunodiagn Immunother 32(4):270-276. https://doi.org/ 10.1089/mab.2013.0007

29. Tanimoto N, Sothilingam V, Kondo M, Biel M, Humphries P, Seeliger MW (2015) Electroretinographic assessment of rod- and cone-mediated bipolar cell pathways using flicker stimuli in mice. Sci Rep 5:10731. https://doi.org/10.1038/srep10731

30. Wang M, Ma W, Zhao L, Fariss RN, Wong WT (2011) Adaptive Muller cell responses to microglial activation mediate neuroprotection and coordinate inflammation in the retina. J Neuroinflammation 8:173. https://doi.org/10.1186/ 1742-2094-8-173

31. Fontaine V, Mohand-Said S, Hanoteau N, Fuchs C, Pfizenmaier K, Eisel U (2002) Neurodegenerative and neuroprotective effects of tumor necrosis factor (TNF) in retinal ischemia: opposite roles of
TNF receptor 1 and TNF receptor $2 \mathrm{~J}$ Neurosci 22(7):RC216. doi: 20026253

32. Kofuji P, Biedermann B, Siddharthan V, Raap M, Iandiev I, Milenkovic I, Thomzig A, Veh RW et al (2002) Kir potassium channel subunit expression in retinal glial cells: implications for spatial potassium buffering. Glia 39(3):292-303. https://doi.org/ 10.1002/glia.10112

33. Raap M, Biedermann B, Braun P, Milenkovic I, Skatchkov SN, Bringmann A, Reichenbach A (2002) Diversity of Kir channel subunit mRNA expressed by retinal glial cells of the Guinea-pig. Neuroreport 13(8):1037-1040

34. Bringmann A, Pannicke T, Grosche J, Francke M, Wiedemann P, Skatchkov SN, Osborne NN, Reichenbach A (2006) Muller cells in the healthy and diseased retina. Prog Retin Eye Res 25(4):397-424. https://doi.org/10.1016/j.preteyeres.2006.05.003

35. Aslanidis A, Karlstetter M, Walczak Y, Jagle H, Langmann T (2014) RETINA-specific expression of Kenv2 is controlled by cone-rod homeobox $(\mathrm{Crx})$ and neural retina leucine zipper $(\mathrm{Nrl})$. Adv Exp Med Biol 801:31-41. https://doi.org/10.1007/978-14614-3209-8 5

36. Skatchkov SN, Eaton MJ, Shuba YM, Kucheryavykh YV, Derst C, Veh RW, Wurm A, Iandiev I et al (2006) Tandem-pore domain potassium channels are functionally expressed in retinal (Muller) glial cells. Glia 53(3):266-276. https://doi.org/10.1002/glia.20280

37. Hurley JB, Lindsay KJ, Du J (2015) Glucose, lactate, and shuttling of metabolites in vertebrate retinas. J Neurosci Res 93(7):10791092. https://doi.org/10.1002/jnr.23583

38. Country MW (2017) Retinal metabolism: a comparative look at energetics in the retina. Brain Res 1672:50-57. https://doi.org/10. 1016/j.brainres.2017.07.025

39. Pasnoor M, Dimachkie MM, Farmakidis C, Barohn RJ (2018) Diagnosis of myasthenia gravis. Neurol Clin 36(2):261-274. https://doi.org/10.1016/j.ncl.2018.01.010

40. Karwoski CJ, Newman EA, Shimazaki H, Proenza LM (1985) Light-evoked increases in extracellular $\mathrm{K}+$ in the plexiform layers of amphibian retinas. J Gen Physiol 86(2):189-213

41. Lei B, Perlman I (1999) The contributions of voltage- and timedependent potassium conductances to the electroretinogram in rabbits. Vis Neurosci 16(4):743-754

42. Haj-Yasein NN, Bugge CE, Jensen V, Ostby I, Ottersen OP, Hvalby O, Nagelhus EA (2015) Deletion of aquaporin-4 increases extracellular $\mathrm{K}(+)$ concentration during synaptic stimulation in mouse hippocampus. Brain Struct Funct 220(4):2469-2474. https://doi.org/ 10.1007/s00429-014-0767-z

43. Rehak M, Hollborn M, Iandiev I, Pannicke T, Karl A, Wurm A, Kohen L, Reichenbach A et al (2009) Retinal gene expression and Muller cell responses after branch retinal vein occlusion in the rat. Invest Ophthalmol Vis Sci 50(5):2359-2367. https://doi.org/10. 1167/iovs.08-2332

44. Iandiev I, Wurm A, Hollborn M, Wiedemann P, Grimm C, Reme CE, Reichenbach A, Pannicke Tet al (2008) Muller cell response to blue light injury of the rat retina. Invest Ophthalmol Vis Sci 49(8): 3559-3567. https://doi.org/10.1167/iovs.08-1723

45. Ruiz-Ederra J, Zhang H, Verkman AS (2007) Evidence against functional interaction between aquaporin- 4 water channels and Kir4.1 potassium channels in retinal Muller cells. J Biol Chem 282(30):21866-21872. https://doi.org/10.1074/jbc.M703236200

46. Ji M, Miao Y, Dong LD, Chen J, Mo XF, Jiang SX, Sun XH, Yang XL et al (2012) Group I mGluR-mediated inhibition of Kir channels contributes to retinal Muller cell gliosis in a rat chronic ocular hypertension model. J Neurosci 32(37):12744-12755. https://doi.org/ 10.1523/JNEUROSCI.1291-12.2012

47. Pruss H, Derst C, Lommel R, Veh RW (2005) Differential distribution of individual subunits of strongly inwardly rectifying potassium channels (Kir2 family) in rat brain. Brain Res Mol Brain Res 139(1):63-79. https://doi.org/10.1016/j.molbrainres.2005.05.006 
48. Pannicke T, Faude F, Reichenbach A, Reichelt W (2000) A function of delayed rectifier potassium channels in glial cells: maintenance of an auxiliary membrane potential under pathological conditions. Brain Res 862(1-2):187-193

49. Harada T, Harada C, Watanabe M, Inoue Y, Sakagawa T, Nakayama N, Sasaki S, Okuyama S et al (1998) Functions of the two glutamate transporters GLAST and GLT-1 in the retina. Proc Natl Acad Sci U S A 95(8):4663-4666

50. Reichenbach A, Bringmann A (2013) New functions of Muller cells. Glia 61(5):651-678. https://doi.org/10.1002/glia.22477

51. Bringmann A, Pannicke T, Biedermann B, Francke M, Iandiev I, Grosche J, Wiedemann P, Albrecht J et al (2009) Role of retinal glial cells in neurotransmitter uptake and metabolism. Neurochem Int 54(3-4):143-160. https://doi.org/10.1016/j.neuint.2008.10.014

52. Soto F, Kerschensteiner D (2015) Synaptic remodeling of neuronal circuits in early retinal degeneration. Front Cell Neurosci 9:395. https://doi.org/10.3389/fncel.2015.00395

53. Busche MA, Chen X, Henning HA, Reichwald J, Staufenbiel M, Sakmann B, Konnerth A (2012) Critical role of soluble amyloidbeta for early hippocampal hyperactivity in a mouse model of Alzheimer's disease. Proc Natl Acad Sci U S A 109(22):8740 8745. https://doi.org/10.1073/pnas.1206171109

54. Busche MA, Eichhoff G, Adelsberger H, Abramowski D, Wiederhold KH, Haass C, Staufenbiel M, Konnerth A et al (2008) Clusters of hyperactive neurons near amyloid plaques in a mouse model of Alzheimer's disease. Science 321(5896):16861689. https://doi.org/10.1126/science. 1162844

55. Reichenbach A, Derouiche A, Kirchhoff F (2010) Morphology and dynamics of perisynaptic glia. Brain Res Rev 63(1-2):11-25. https://doi.org/10.1016/j.brainresrev.2010.02.003

56. Bringmann A, Uckermann O, Pannicke T, Iandiev I, Reichenbach A, Wiedemann P (2005) Neuronal versus glial cell swelling in the ischaemic retina. Acta Ophthalmol Scand 83(5):528-538. https:// doi.org/10.1111/j.1600-0420.2005.00565.x
57. Izumi Y, Kirby CO, Benz AM, Olney JW, Zorumski CF (1999) Muller cell swelling, glutamate uptake, and excitotoxic neurodegeneration in the isolated rat retina. Glia 25(4):379-389

58. Izumi Y, Shimamoto K, Benz AM, Hammerman SB, Olney JW, Zorumski CF (2002) Glutamate transporters and retinal excitotoxicity. Glia 39(1):58-68. https://doi.org/10.1002/glia.10082

59. Jeong S (2017) Molecular and cellular basis of neurodegeneration in Alzheimer's disease. Mol Cell 40(9):613-620. https://doi.org/10. 14348/molcells.2017.0096

60. Gazit N, Vertkin I, Shapira I, Helm M, Slomowitz E, Sheiba M, Mor Y, Rizzoli S et al (2016) IGF-1 receptor differentially regulates spontaneous and evoked transmission via mitochondria at hippocampal synapses. Neuron 89(3):583-597. https://doi.org/10.1016/j. neuron.2015.12.034

61. Faits MC, Zhang C, Soto F, Kerschensteiner D (2016) Dendritic mitochondria reach stable positions during circuit development. eLife 5:e11583. doi:https://doi.org/10.7554/eLife.11583

62. Lin J, Wu PH, Tarr PT, Lindenberg KS, St-Pierre J, Zhang CY, Mootha VK, Jager S et al (2004) Defects in adaptive energy metabolism with CNS-linked hyperactivity in PGC-1alpha null mice. Cell 119(1):121-135. https://doi.org/10.1016/j.cell.2004.09.013

63. Gouras P, MacKay CJ (1992) Supernormal cone electroretinograms in central retinal vein occlusion. Invest Ophthalmol Vis Sci 33(3): 508-515

64. Miyata R, Kondo M, Kato K, Sugimoto M, Matsubara H, Ikesugi K, Ueno S, Yasuda S et al (2018) Supernormal flicker ERGs in eyes with central retinal vein occlusion: clinical characteristics, prognosis, and effects of anti-VEGF agent. Invest Ophthalmol Vis Sci 59(15):5854-5861. https://doi.org/10.1167/iovs.18-25087

Publisher's Note Springer Nature remains neutral with regard to jurisdictional claims in published maps and institutional affiliations. 